\title{
Políticas públicas: Ecoturismo x preservação dos recursos naturais
}

\author{
Public politics: Ecotourism $X$ preservation of natural \\ resources
}

\author{
Luís Carlos Araújo Moraes
}

\begin{abstract}
RESUMO
As políticas públicas ocupam importante papel no âmbito do planejamento estratégico e da gestão pública nos mais diferenciados setores. Sendo assim, este estudo tem como objetivo analisar a política pública de meio ambiente, tendo como foco principal o Plano Diretor da APA da Serrinha do Alambari, no município de Resende/RJ e sua correlação com a política setorial de turismo inscrita no Plano Diretor Municipal. A pesquisa se caracteriza como exploratória e de abordagem qualitativa, com estudo de caso. O resultado aponta para a falta de sinergia entre as políticas ambiental e a de turismo, comprometendo, pois, não só a atividade turística como a preservação do patrimônio natural. Espera-se que os dados e as informações obtidas norteiem o poder público para que sejam desenvolvidas ações efetivas, através das políticas públicas, para compatibilizar a prática do ecoturismo com a preservação e conservação dos recursos naturais, ambas pautadas na ótica do desenvolvimento sustentável.
\end{abstract}

PALAVRAS-CHAVE: Planejamento; Política Pública; Ecoturismo; Meio Ambiente.

\section{ABSTRACT}

Public politics have important role in the strategic planning and management of public in more differentiated sectors. Thus, this study aims to analyze the public environmental politic, focusing mainly on the Master Plan of the Serrinha Alambari Protect Area in the municipality of Resende (RJ, Brazil) and its correlation with the sectoral politic entered in the tourism Master Plan. The research is characterized as exploratory and qualitative approach with case study. The result points to the lack of synergy between environmental and tourism politics, compromising therefore not only to tourism activity as the preservation of natural heritage. It is expected that the data and information obtained will guide the government to be developed effective actions, through public politics, in order to reconcile the practice of ecotourism with the preservation and conservation of natural resources, both predicated in optics of sustainable development.

KEYWORDS: Planning; Public Politic; Ecotourism; Environment. 


\section{Introdução}

Os estudos sobre políticas públicas ainda são muito recentes existindo, ainda, muitas divergências conceituais. Segundo Secchi (2010), qualquer definição de política pública é arbitrária, pois não há consenso na literatura especializada sobre questionamentos básicos.

Para Heclo (1972), uma política pode ser considerada como um curso de uma ação ou inação, mais do que decisões ou ações específicas. Easton (1953) considera como um conjunto de decisões que alocam valor. Jenkins (1978) vai além, vê como um conjunto de decisões interrelacionadas e, Cruz (2006), corrobora neste sentido relatando que as políticas nas esferas regional ou federal não excluem as políticas em nível local e todas devem ser convergentes, indo ao encontro da Lei Complementar $n^{\circ} 140 / 11$ que descreve nos objetivos comuns a União, Estados, Distrito Federal e Municípios, dentre outros, a harmonia entre as políticas e ações administrativas para evitar a sobreposição de atuação entre os entes federativos, de forma a evitar conflitos de atribuições, garantindo uma atuação administrativa eficiente (BRASIL, 2011).

As políticas públicas envolvem vários atores, com diferentes interesses, o que muitas das vezes as tornam ineficazes, com consequências indesejáveis para a população de uma forma geral, ou seja, na fase da elaboração da política pública, se não houver uma integração entre as partes envolvidas, todas com o mesmo peso de imposição e negociação de seus interesses, o resultado final será um projeto parcial, fragmentado, uma política governamental. Ressalta-se que para serem públicas faz-se necessário considerar a quem se destinam os resultados bem como seus benefícios. Para isso sua construção deve ser orientada pelo debate público.

O estudo das políticas públicas de turismo tem ampliado sua importância devido ao crescimento da atividade no país. A atividade turística tem sido divulgada como uma alternativa para o desenvolvimento social onde é praticado, além de gerar recursos para proteção e conservação dos recursos culturais e naturais existentes na localidade. Neste sentido, de acordo com Castro (1998), a opção política por privilegiar a atividade turística no conjunto das ações produtivas tem bases bem definidas. Para 0 autor, o poder público reconhece o turismo como atividade geradora de emprego e renda, contribuindo desta maneira para o processo de desenvolvimento econômico, constituindo o principal compromisso da public choice, muito embora esse "poder", inerente da atividade turística, encobre em suas estatísticas fatos que certamente são importantes para 0 planejamento da atividade.

Entretanto, esse desenvolvimento pode não ocorrer, gerando diversos impactos socioambientais. Segundo Cruz (2000), tais impactos se dão, sobretudo, na sua disposição de organizar sociedades inteiras e de condicionar o re-ordenamento de território para que a atividade possa acontecer. Para tanto, cabe ao poder público municipal disciplinar suas ações bem como as do setor privado, através de um conjunto de políticas públicas.

Assim sendo, para atingir os resultados em diversas áreas e promover o bem-estar da população, os governos se utilizam de Políticas Públicas que 
podem ser definidas como um conjunto de ações e decisões do governo, voltadas para solucionar os problemas da sociedade. Dito de outra maneira, pode-se dizer que são a totalidade de ações, metas e planos que os governos - em todos os níveis, traçam para alcançar o bem-estar da sociedade e o interesse público (SEBRAE/MG, 2008).

Entretanto, as ações que os gestores públicos selecionam como prioridades são aquelas que eles entendem serem as demandas ou expectativas da sociedade, o que quer dizer que nem sempre as ações são as de interesse da sociedade. Neste caso, o bem-estar da sociedade é sempre definido pelo governo. Isto ocorre porque a sociedade nem sempre consegue se expressar de forma integral.

\section{Elaboração de políticas públicas: conflitos de interesses}

A partir da Constituição Federal - CF de 1988 os municípios adquiriram autonomia política, ampliando suas competências naquilo que lhe é direito, ou seja, legislar sobre assuntos de interesse local, assim definidos no art. 30 da Carta Magna.

Desta forma, a concepção de uma política pública nasce enraizada na ideia de intervenção do Estado com objetivo de prover serviços e condições destinados a minimizar as desigualdades sociais e promover 0 desenvolvimento local. Nesse sentido, só poderia ser elaborada e executada por agentes públicos, ou seja, funcionários públicos que compõe a burocracia estatal. Poderia, porque a Constituição de 1988 atribui aos demais atores sociais uma participação significativa em toda elaboração e monitoramento dessas políticas.

Contudo, a visão, muita das vezes oportunista sobre a formulação de políticas públicas implica reconhecer apenas a burocracia estatal como protagonista de todo o processo de construção e execução dessas políticas, uma vez que na maioria das vezes essas são pensadas pelos chamados cargos comissionados, ou seja, cargos de livre provimento dos políticos eleitos enquanto os funcionários de carreira, que desenvolvem funções técnicas não têm voz ativa. Isso acontece devido aos interesses políticos como o uso de Secretarias como moeda de troca e em ações de curto prazo - políticas governamentais, em detrimento as de longo prazo.

Outro viés de conflito na construção de políticas públicas é no sentido de satisfazer aos interesses dos fornecedores e prestadores de serviços ao poder público, tendo em vista ser o Estado, muita das vezes, seu principal cliente e financiador de campanhas eleitorais. Situação esta que pode gerar uma ingerência na elaboração da política. A sociedade civil, terceiro ator da política, também é composta de uma variedade de interesses. Representada muita das vezes por diversos movimentos sociais, com pretensões específicas, a pessoa comum, beneficiária da política, vê em muitos casos seus interesses não satisfeitos em sua totalidade em atendimento as especificidades de ONG's, como por exemplo.

Daí depreende-se que a ética, o respeito aos direitos humanos, a preocupação com o desenvolvimento sustentável e com a qualidade de vida de vida dos moradores local além do atendimento ao visitante, não são foco 
de preocupação e não alicerçam as ações organizacionais (Zouain \& Cruz, 2004).

\section{Política Pública de Turismo}

Para o Plano Nacional de Turismo - PNT,

o turismo no Brasil contemplará as diversidades regionais, (....) a criação de emprego e ocupação, a geração e distribuição de renda, a redução das desigualdades sociais e regionais, a promoção da igualdade de oportunidades, o respeito ao meio ambiente, a proteção ao patrimônio histórico e cultural e a geração de divisas ... (BRASIL, 2007).

Neste sentido, muito embora não seja atribuição do turismo resolver problemas sociais ou econômicos dos lugares, entende-se que a atividade turística, quando planejada de forma responsável, tem a capacidade de minimizá-los. Deriva deste fato a necessidade de se fazer um planejamento sistemático para a atividade, visto sua importância para a economia local.

De fato, segundo Custódio (2004) o Brasil se coloca junto ao mercado internacional e nacional como uma primorosa opção de investimento no setor turístico, considerando suas ofertas, principalmente, natural, no entanto, a falta de infraestrutura básica e turística não recebe a atenção que merece para que esse investimento se torne real.

Isto posto, e uma vez que é de responsabilidade dos municípios a determinação do nível de turismo que se deseja para a localidade, bem como as resoluções dos diversos problemas sociais que afligem a população, confere-se ao Estado, por meio da administração pública nos três âmbitos, federal, estadual e municipal, o planejamento da atividade turística além de assegurar os direitos descritos no artigo terceiro da nossa Constituição.

A má gestão pública alheia às benfeitorias locais e/ou ausência de políticas de preservação e conservação de bens culturais e naturais têm sido fatores determinantes na degradação das paisagens, afastando definitivamente a possibilidade de se trabalhar a atividade turística na localidade.

Outra forma de degradação, para Cruz (2001) são os impactos do turismo em ambientes naturais associados tanto a instalação de infraestrutura básica nas localidades para que o turismo possa acontecer, quanto da infraestrutura turística como meios de hospedagens e restaurantes edificados em áreas naturais, comprometendo a biodiversidade local.

Não obstante ao papel do Estado, entende-se de fundamental importância o papel do setor privado para o desenvolvimento da atividade turística das localidades, uma vez que depende dele o provento da 
infraestrutura de apoio. Fato este de grande preocupação também do Plano Nacional.

Entretanto, muita das vezes, fica evidenciada a falta de ética por parte de empresários que maximizam os lucros a qualquer preço. Portanto, devese buscar um entrosamento maior entre os dois setores para que a atividade aconteça de forma justa e responsável.

Wanhill (1997, apud BARBOSA; ZAMOT, 2004, p.93) afirma que "as políticas públicas adotadas por um município para o desenvolvimento do turismo determinarão os vetores de crescimento da atividade e a ações de setor privado".

Petrocchi (1998) afirma que a falta de planejamento na expansão da urbanização em países emergentes traz sérios problemas como crescimento desordenado, deficiência na infraestrutura básica, falta de segurança, baixa qualidade habitacional, entre outros, afetando diretamente a qualidade de vida local, que por sua vez prejudica o turismo.

De acordo com Luchiari (2004, p.108), "a urbanização turística coloca as cidades no mercado de paisagens naturais e artificiais". Ainda segundo a autora, muitas cidades (re) organizam a paisagem com o objetivo de tornálas um atrativo para a atividade turística.

Segundo Cruz (2001), somente o planejamento físico-territorial é capaz de minimizar ou até evitar os impactos negativos da infraestrutura básica sobre o ambiente. Daí a origem de diversos impactos ambientais negativos em áreas urbanas, como por exemplo, poluição das águas e do solo em função do excesso de lixo deixado pelo visitante.

Portanto, cabe ao poder público, através, principalmente, do seu Plano Diretor, do Zoneamento Ecológico Econômico e do Licenciamento Ambiental, minimizar o conflito entre ocupação humana, economia e preservação ambiental.

Por fim, entende-se que a dimensão política assegura a execução de todos os demais critérios para o desenvolvimento da atividade turística de maneira responsável. A atuação do poder público se torna ainda mais fundamental no que diz respeito à melhoria da qualidade de vida da população para que não haja conflito entre o visitante e os autóctones.

\section{Política pública ambiental no processo de planejamento do setor turístico}

$\mathrm{Na}$ medida em que os níveis de urbanização crescem, crescem também os problemas ambientais. Temas pertinentes ao ambiente urbano têm sido reconhecidos por diversos autores e, políticas públicas ambientais são tidas como vitais para qualquer estratégia efetiva de desenvolvimento urbano. Contudo, a inclusão das políticas ambientais no rol das políticas públicas só aconteceu recentemente.

De acordo com Alves (2009), a área ambiental tem estado sujeita aos mesmos desgostos e empecilhos que nortearam a condução das políticas econômicas e sociais nos últimos anos, ou seja, a influência de fatores 
econômicos na tomada de decisões, o não cumprimento do planejamento estabelecido nos programas de Governo, acrescidos de um fraco posicionamento de intersetorialidade ocasionam a ineficiência das políticas sociais, que repercutem de maneira similar na área ambiental.

$\mathrm{Na}$ Constituição Federal - C.F $\overline{\bar{y}}_{2}$ a proteção do meio ambiente e salvaguarda da sadia qualidade de vida são asseguradas através da implementação de políticas públicas. Segundo Leff (2001), qualidade de vida pode ser definida como o produto da sociedade pós-materialista, que satisfaz as necessidades de caráter mais qualitativo desviando atenção das necessidades básicas promovidas pelas políticas do bem-estar do Estado.

O problema, segundo Mota, Pereira E Pereira (2007) é que embora se apregoe a superação dos valores materiais, ou seja, dos hábitos de consumo, constata-se a massificação dos mesmos, a deterioração do ambiente e as limitações do Estado em prover os serviços básicos à população marginalizada do ciclo produção versus consumo, gerando, pois, contradições entre o social e o ambiental com declínio da qualidade de vida. Como exemplo de políticas públicas cita-se a Política Nacional do Meio Ambiente (BRASIL, 1981) e o Estatuto da Cidade (BRASIL, 2001), ambas em nível federal.

O objetivo do Estatuto da Cidade é ordenar o pleno desenvolvimento das funções sociais da cidade e da propriedade urbana, mediante diretrizes, entre elas a ordenação e controle do uso do solo de forma a evitar a deterioração das áreas urbanas, da poluição e da degradação ambiental (BRASIL, 2001).

Neste sentido, a relação entre o desenvolvimento desordenado do turismo e a degradação do ambiente onde ele é praticado, deve fazer parte do processo de planejamento e implementação das políticas públicas tanto relacionadas ao meio ambiente quanto ao turismo (OLIVEIRA, 2002).

Já a Política Nacional do Meio Ambiente objetiva a compatibilização do desenvolvimento econômico social com a preservação da qualidade do meio ambiente e do equilíbrio ecológico e tem como um dos princípios a racionalização do uso do solo (BRASIL, 1981). Percebe-se, pois, a compatibilização das Leis.

As normas de competência concebida pela C.F. atribuem aos entes federados matérias gerais e específicas para melhor administrar suas unidades federativas e proporcionar bem-estar à população, cabendo aos municípios à competência de legislar sobre assuntos de interesse local e de suplementar a legislação federal e estadual, nos termos do art. 308 da CF.

Dentre os desafios da atualidade que os governos enfrentam estão temas polêmicos como saneamento básico, disposição final de resíduos sólidos e a arborização urbana. Apesar da existência das garantias constitucionais e da legislação infraconstitucional que proíbem o lançamento de esgotos, sem o devido tratamento, em corpos hídricos, exigem o deposito do lixo em aterros sanitários, e que restringe o corte de árvores, verifica-se ausência de eficácia dessas garantias pela não aplicação efetiva dessas políticas públicas pelo Poder Público. 
Na seara ambiental, o agir administrativo está repleto de deveres para conservação e preservação do ambiente, imposto por ordem infraconstitucional, como nos casos da Política Nacional do Meio Ambiente e Lei Federal $n^{\circ}$ 6.938/81, além da Constituição Federal. A inércia de atuação e fiscalização do Estado traz consequências trágicas aos interesses da sociedade, ao ambiente, por conseguinte, à qualidade de vida da população.

Considera-se que as paisagens naturais e a cultura local, ambos pelas suas especificidades, são os principais atrativos turísticos do país. Preserválas já seria motivo suficiente para incorporar parâmetros responsáveis e harmoniosos ao turismo, visto que seria razoável preservar as paisagens que motivaram sua visitação. Tornar viável a atividade turística requer ainda um comportamento responsável em relação ao ambiente, seja ele natural ou urbano, e uma atenção específica aos aspectos naturais que envolvem as localidades.

O comportamento responsável, no que diz respeito ao planejamento estratégico do turismo, tem início no poder público local, uma vez que é ele que determina o nível de turismo que se deseja ter no município. O poder público deve fazer a gestão pública da paisagem baseado no plano diretor municipal, no zoneamento ecológico econômico e no licenciamento ambiental de atividades considerada de alto potencial poluidor.

Para tanto deve-se ter uma concepção integrada e sistêmica dos fenômenos físicos, biológicos e sociais, uma vez que esses fenômenos atuam de forma interdependente e possuem uma inter-relação entre eles.

Neste contexto, as cidades precisam buscar soluções para problemas como os de abastecimento de água, tratamento de esgoto, disposição final de resíduos sólidos, licenciamento ambiental de atividades com alto potencial poluidor, vegetação urbana, transito e muitos outros, que influenciam diretamente a paisagem, afetando a atividade turística além de gerar desconforto na população local, alterando sua qualidade de vida.

Já a compreensão espacial complementa a ambiental, na medida em que indica a necessidade de delimitar o fluxo de turistas e empreendimentos que o destino turístico pode receber sem comprometer os ecossistemas locais. Essa delimitação do fluxo de turistas se dá através da determinação da capacidade de carga turística.

O conceito de capacidade de carga está ligado às variáveis ecológicas, sociais e culturais. Para a Organização Mundial de Turismo (OMT, 2001), capacidade de carga turística é o máximo de uso que se pode fazer dos recursos naturais sem causar impactos negativos sobre esses e sobre as comunidades autóctones, sem reduzir a satisfação dos visitantes.

\section{Política Pública de Turismo em Unidades de Conservação}

A Lei Federal 9.985/000 que instituiu o Sistema Nacional de Unidades de Conservação da Natureza - SNUC, define Unidade de Conservação UC, como espaço territorial e seus recursos ambientais, incluindo as águas jurisdicionais, com características naturais relevantes, legalmente instituído pelo Poder Público, com objetivos de conservação e limites definidos, sob 
regime especial de administração, ao qual se aplicam garantias adequadas de proteção (BRASIL, 2000).

As UC's, segundo SNUC são divididas em dois grupos: Unidades de Proteção Integral e Unidades de Uso Sustentável. Fazem parte do primeiro grupo as Estações Ecológicas, Reservas Biológicas, Parques Nacionais, Monumentos Naturais e Refúgios de Vida Silvestre. Dentre as de Uso Sustentáveis destacam-se as Áreas de Proteção Ambiental, Áreas de Relevante Interesse Ecológico, Florestas Nacionais, Reservas Extrativistas, Reservas de Fauna, Reservas de Desenvolvimento Sustentável e Reservas Particulares do Patrimônio Natural (BRASIL, 2000).

Dentre os objetivos gerais do SNUC destaca-se a prática do turismo ecológico e entre suas diretrizes a lei assegura a participação efetiva das populações locais na criação, implantação e gestão das UC's, envolvimento da sociedade na revisão da política de UC's bem como apoio e cooperação de organizações não governamentais, de organizações privadas e pessoas físicas para o desenvolvimento de estudos, pesquisas científicas, práticas de educação ambiental, atividades de lazer e de turismo ecológico, monitoramento, manutenção e outras atividades de gestão das unidades de conservação (BRASIL, 2000).

O Turismo Responsável apresenta-se como uma alternativa não só para a preservação das características do ambiente local, mas também na melhoria das condições socioeconômicas das comunidades onde ele é praticado.

Assim, ao desenvolvê-lo, mister se faz adotar ações direcionadas ao seu planejamento e gestão, visando minimizar os impactos negativos e maximizar os positivos que a atividade turística exercerá sobre o local, especialmente em uma UC.

Neste contexto, as Diretrizes para a Política Nacional de Ecoturismo, define ecoturismo como "um segmento da atividade turística que utiliza de forma sustentável o patrimônio natural e cultural, incentiva sua conservação e busca a formação de uma consciência ambientalista através da interpretação do ambiente, promovendo o bem-estar das populações envolvidas" (BRASIL, 1994, p.19).

Para o The Ecotourism Society ecoturismo é uma viagem responsável e que visa preservar o meio ambiente e promover o bem-estar da população local. Percebe-se que segundo definição o ecoturismo encontra respaldo nos princípios da responsabilidade social, no momento em que se acredita que não se pode preservar a natureza à custa da população local. Logo é visto por muitos como sendo um meio eficaz de preservação do ambiente natural e, por isso interessa aos defensores do desenvolvimento sustentável.

Em contrapartida, autores como Souza (2000), Santos Filho (apud BAHL, 2003) e Frey (2001), dentre outros, questionam o conceito de desenvolvimento sustentável.

Cabe ressaltar que o conceito de turismo sustentável derivou-se do conceito de desenvolvimento sustentável oriundo do Relatório Brundland. Sendo assim, o conceito de turismo vem carregado de nomenclaturas, tipologias e definições por diversos autores, porém são quase inexistentes 
as diferenças entre eles, existindo, pois, somente diferenciação na forma de se praticar a atividade: turismo de massa (convencional) ou o dito turismo alternativo (verde, suave, etc.).

Segundo Wheeller (1991, p.93)

o turismo sustentável queimou-se a si próprio, através de objetivos conflituais e incompatíveis: pequena escala compreensiva, número limitado de visitantes, viabilidade econômica, rendimentos significativos e impactos no aumento de empregos.

Soma-se a isto, o fato de ser incompatível a sustentabilidade com a atual forma de governo existente no mundo (leia-se capitalismo) onde a operacionalização da prática sustentável se torna extremamente difícil, se não impossível.

Marcado por essa ambiguidade entende-se que o mais adequado é adotar o conceito de turismo responsável. Um conceito de turismo responsável é apresentado por Salvatti (2004, p.16), onde o autor demonstra uma preocupação maior com a inclusão e melhoria da qualidade de vida das comunidades locais, ponto este que o conceito de sustentabilidade não prioriza.

\begin{abstract}
O turismo responsável, no contexto de uma estratégia para a sustentabilidade ampla dos destinos turísticos, é aquele que mantém e, onde possível, valoriza as características dos recursos naturais e culturais nos destinos, sustentandoas para as futuras gerações de comunidades, visitantes e empresários.
\end{abstract}

Não obstante a discussão acima mencionada, para a Organização Mundial do Turismo (OMT, 2003) o turismo sustentável deve levar em consideração todos os aspectos da diversidade cultural e institucional, privilegiando aspectos físicos e ambientais capazes de influenciar diretamente nas condições de saúde, qualidade de vida e segurança das pessoas e comunidades. Para Mclyntyre (1993), o desenvolvimento sustentável do turismo engloba basicamente 0 setor econômico, 0 sociocultural e o ambiental.

Neste sentido, Ansarah (2001, p.30) relata que

o estudo do turismo deve ser direcionado para o desenvolvimento sustentável, conceito essencial para alcançar metas de desenvolvimento sem esgotar os recursos naturais e culturais nem deteriorar 0 meio ambiente, entende-se que a proteção do meio ambiente e o êxito do desenvolvimento turístico são inseparáveis. 
Neste cenário surge a necessidade de se trazer a dimensão ambiental para a dinâmica do desenvolvimento da atividade turística. De acordo com a International Union for the Conservation of the Nature - IUCN, a criação de UCs é à medida que melhor exemplifica, na atualidade, a tentativa de preservar os recursos naturais nessas áreas protegidas, da melhoria da qualidade de vida das populações locais, além da satisfação dos visitantes do destino.

\section{Método}

$\mathrm{Na}$ temática que trata das políticas sociais no Brasil, observa-se significativa literatura sobre 0 tema nas mais diversas áreas do conhecimento. $\mathrm{Na}$ bibliografia existente, as conotações relativas à formulação e avaliação de políticas públicas recebem um tratamento mais quantitativo, se comparados com o tratamento dedicado à implementação dessas políticas, como vários autores consultados a respeito do tema confirmam. Nesse contexto, tais conotações sobre o tratamento dedicado a implementação das políticas em questão representam tema de destaque tratado neste estudo.

Sendo assim, quanto à abordagem a pesquisa utilizada foi à qualitativa, uma vez que se busca explicar o porquê das coisas. O objetivo da amostra, segundo Deslauriers (1991) é de produzir informações aprofundadas e ilustrativas, sendo fundamental que ela seja capaz de produzir novas informações. Portanto, a pesquisa qualitativa se preocupa com aspectos da realidade que não podem ser quantificados, centrando-se na compreensão e explicação da dinâmica das relações sociais.

Para Minayo (2001), a pesquisa qualitativa trabalha com o universo de motivos, aspirações, atitudes, correspondendo a um espaço mais profundo das relações, dos processos e dos fenômenos que não podem ser reduzidos à operacionalização de variáveis. Ainda segundo autor, a pesquisa qualitativa trabalha com o universo de significados, motivos, aspirações, crenças, valores e atitudes, o que corresponde a um espaço mais profundo das relações, dos processos e dos fenômenos que não podem ser reduzidos à operacionalização de variáveis. A pesquisa qualitativa preocupa-se, portanto, com aspectos da realidade que não podem ser quantificados, centrando-se na compreensão e explicação da dinâmica das relações sociais.

Cabe ressaltar que de acordo com Minayo e Minayo-Gómez (2003) não existe um método melhor do que o outro. O método mais adequado será sempre aquele capaz de conduzir o investigador a alcançar as respostas para suas perguntas. Os autores ainda entendem que a questão central da cientificidade está calcada na qualidade da pesquisa, não importando se a abordagem é quantitativa ou qualitativa, e sim sua pertinência, relevância e uso adequado de todos os instrumentos.

Do ponto de vista dos objetivos, classifica-se a pesquisa como do tipo exploratória. Este tipo de pesquisa tem como objetivo proporcionar maior familiaridade com o problema, com vistas a torná-lo mais explícito ou a 
construir hipóteses. A grande maioria dessas pesquisas envolve 0 levantamento bibliográfico.

Assim, a pesquisa abarcou os seguintes procedimentos:

$>$ pesquisa bibliográfica: já que toda pesquisa se inicia por ela. Foi realizada através de pesquisa em livros, periódicos e de web sites, para identificar o estado da arte e fazer uma revisão teórica da construção de políticas públicas envolvidas no estudo.

$>$ pesquisa documental: para obtenção de informações específicas sobre as políticas públicas voltadas para a área ambiental e de turismo, especificamente ecoturismo junto a órgão oficiais.

$>$ Pesquisa tipo estudo de caso: esta modalidade de pesquisa caracteriza-se por grande flexibilidade. Um estudo de caso pode ser caracterizado como um estudo de uma entidade bem definida como, por exemplo, um programa, uma instituição, dentre outros (TRIVIÑOS, 1987). O pesquisador pretende revelar o objeto a ser estudado tal como ele o percebe.

\section{Resultado e Discussão}

\section{Caracterização da área de estudo}

Com área total de aproximadamente 5.500 ha e espaço territorial entre as cotas de 700 e $2.300 \mathrm{~m}$, divisa com entorno leste do Parque Nacional do Itatiaia (PNI) - Serra da Mantiqueira e localizada a $14 \mathrm{~km}$ do centro urbano de Resende, a Serrinha do Alambari abrange ainda a comunidade de Capelinha. A Serrinha do Alambari abrange a parte alta das microbacias dos rios Alambari e Pirapitinga, pertencentes à Bacia do Rio Paraíba do Sul.

A Serra da Mantiqueira guarda importantes remanescentes de Mata Atlântica, que possui alta prioridade para conservação dos recursos naturais, devido restar apenas cerca de $8,5 \%$ de sua área original (SOS MATA ATLANTICA, 2013). A grande riqueza de espécies de fauna e de flora, com alto grau de endemismo, confere extrema importância à região no que diz respeito à conservação e preservação desses recursos além de estudos científicos.

A APA da Serrinha do Alambari - APASA, criada pela Lei Municipal $n^{\circ}$ 1.726/91, conta com excelente condição de preservação de seu ecossistema, protegendo a parte alta das microbacias dos rios Alambari e Pirapitinga. Protegida por um Plano Diretor específico é admirada por sua paisagem montanhosa e belas cachoeiras, rios de águas límpidas e frias, perfeitas para a criação de trutas, além de ser considerada Estância Climática.

A APASA se enquadra numa área de uso direto dos recursos naturais. Dentre os tipos de uso diretos destaca-se a presença de moradia, turismo, atividades econômicas e etc.

Pelo acima exposto, a localidade segue uma das principais rotas turísticas do sul do estado do Rio de Janeiro que dá acesso ainda às regiões de Visconde de Mauá, Maringá, Maromba além do PNI. 
Em relação aos resultados, o primeiro argumento para se questionar é a proposta turística para a APASA. Partindo do princípio de que o Plano de Manejo é o principal instrumento de gestão de uma U.C $\overline{\bar{j}}_{1}$ pois define as normas de uso da área, o manejo dos recursos naturais além dos programas de sustentabilidade ambiental e socioeconômica observa-se que o mesmo não faz nenhuma menção a prática da atividade turística dentro da sua área.

O art. 116 da Lei Orgânica do Município de Resende, muito embora faça citação quanto às áreas de interesse turístico, ambiental, histórico e urbanístico as quais serão colocadas sob proteção especial do Poder Público e, terão estabelecidas em legislação própria as condições de utilização e ocupação, incluindo-se entre as obrigações de seus proprietários e usuários a conservação dos recursos naturais e paisagísticos e a reparação, reposição ou restauração dos recursos naturais danificados pela sua má utilização, não se encontrou nenhuma legislação pertinentes aos itens acima citados.

Ainda na Lei Orgânica, no seu cap. III - do Meio Ambiente, a legislação também condiciona os componentes que justifiquem sua proteção a serem especialmente protegidos conforme lei específica, apesar de ainda carecer de tal legislação.

No cap. III, art. 162, a legislação informa que, além de outros, a atividades e empreendimentos e a exploração de recursos naturais de qualquer espécie, quer pelo setor público, quer pelo setor privado, só serão admitidas se houver resguardo do meio ambiente à outorga de licença ambiental por órgão ou entidades governamentais competentes, leia-se Agencia do Meio Ambiente de Resende - AMAR, observados os critérios, normas e padrões estabelecidos pelo Poder Público e em conformidade com o planejamento e zoneamento ambientais. Entretanto, o município não tem nenhum controle sob a prática da atividade turística, pois, como se sabe traz inúmeros impactos não só ambientais, mas, sociais e culturais à localidade onde é praticado.

No seu art. 164 a lei imputa ao Município a criação de um sistema de administração da qualidade ambiental, proteção, controle e desenvolvimento do meio ambiente e uso adequado dos recursos naturais, para organizar, coordenar e integrar as ações de órgãos e entidades da administração pública direta e indireta, assegurando a participação comunitária com o fim de propor uma política municipal de proteção ao meio ambiente, proteção a fauna e a flora, vedando práticas que coloquem em risco sua função ecológica e que provoquem extinção de espécies ou submeta os animais a crueldade. Com relação a este artigo, nota-se também a falta de tal sistema que permita o efetivo e eficaz controle de práticas lesivas ao ambiente bem como um sistema de avaliação posterior a tais medidas.

O art. 172 da lei supracitada cria o Parque da Serrinha e considera os seguintes princípios: I - preservação e proteção do ecossistema; II - proteção ao processo evolutivo das espécies; III - preservação e proteção dos recursos naturais, não trazendo qualquer menção a pratica do ecoturismo no seu território.

Já o Plano Diretor traz no seu art. 6, sobre diretrizes da política para o planejamento territorial do Município o desenvolvimento do turismo de 
negócio e de lazer somente e não a outro segmento da atividade e, no seu art. 32 dentre as ações estratégicas do município o desenvolvimento e fortalecimento do potencial turístico de forma sustentável assim como a sensibilização da sociedade para o valor da preservação do patrimônio histórico cultural e da memória do Município, esquecendo, pois, do seu patrimônio natural.

Não obstante a "importância" que o município dispensa ao turismo com dois Órgãos: Secretaria de Turismo e Eventos e Superintendência de Turismo, com cerca de 44 cargos comissionados e 24 funcionários de carreira, totalizando 68 servidores, nenhum sequer com formação acadêmica em Turismo, conclui-se a total falta de planejamento estratégico e comprometimento com a atividade turística no município, resultando na total falta de sinergia entre as políticas públicas de meio ambiente e turismo, esta última inexistente.

\section{Recomendações}

Stiefel e Wolfe, (1994) relatam que o planejamento estratégico deve considerar os aspectos históricos, culturais, sociais, econômicos, ambientais e políticos, não se restringindo a mero exercício de engenharia.

Em 2003, a OMT apresentou uma lista de indicadores considerados centrais para o turismo sustentável. A lista contém onze indicadores e três índices compostos que ajudam no gerenciamento e planejamento do destino.

O Conselho Brasileiro para o Turismo Sustentável e autores como Getz (1987), Garrod e Fyall (1998), Hawkins e Lindedberg (1999), Swarbrooke (2000), Dutton \& Hall (Apud HALL, 2001), Goeldner, Ritchie e Mclntosh (2002), Maroti (2002), Moraes (2014) dentre outros, identificam procedimentos comuns que devem estar presentes no planejamento da atividade turística na fase da elaboração das políticas públicas.

\section{Considerações finais}

Atualmente, palavras como cidadania, sustentabilidade e responsabilidade socioambiental, dentre outras, ganham destaque nos estudos relacionados com a atividade turística. No entanto, essas palavras não passarão de falácias se não vierem acompanhadas de medidas efetivas objetivando a mudança socioambiental do status quo local.

Apesar do acordo firmado entre o Ministério do Meio Ambiente e o do Turismo, em 2005, para elaboração de uma Agenda Ambiental para o Turismo, ações governamentais municipais não tem considerado a relação do crescimento da atividade ecoturística aliada à preservação e conservação dos recursos naturais que justificaram esse crescimento. Tal fato se deriva da falta de planejamento da atividade e ações isoladas. Com isso, o potencial natural existente, assim como os moradores locais não são favorecidos pelos benefícios que a atividade turística pode gerar e, por outro lado, ficam transparentes os impactos negativos oriundos do turismo. 
Este artigo teve como objetivo analisar a política ambiental e sua relação com a política de turismo visto a dependência desta com a primeira. Diante do contexto apresentado neste estudo, concluiu-se a total falta de sinergia entre as políticas citadas, comprometendo, pois, tanto a futura prática do ecoturismo quanto a preservação dos recursos naturais da área em questão.

A utilização de políticas públicas mais efetivas, que se interagem e, integram os aspectos socioambientais exercem um papel decisivo no fomento e manutenção da atividade turística e preservação dos atrativos naturais.

Ações como regulamentação da atividade, interação interinstitucional, formação e capacitação de recursos humanos, avaliação sistemática e controle de qualidade do produto, participação comunitária, conscientização e informação ao visitante, implantação e adequação da infraestrutura básica e turística e gerenciamento de informações, dentre outras, devem ser prioritárias antes do fomento da atividade.

Assim, fica a contribuição e a importância deste estudo apresentado como referência para o planejamento estratégico do turismo, buscando-se maximizar seus aspectos positivos e minimizar os negativos, auxiliando na tomada de decisão.

Ressalta-se que os resultados aqui apresentados constituem o início do processo de implantação de políticas para a prática do ecoturismo como alternativa de conservação e preservação do patrimônio natural, por conseguinte, de um desenvolvimento local.

\section{Referências Bibliográficas}

ALVES, J.A.B. Políticas Sociais, Meio Ambiente e Desenvolvimento Local: uma reflexão sobre o município de Canoinhas - SC . Disponível em: http://works.bepress.com/cgi/viewcontent.cgi?article=1004\&context=jorgeab alves. Acesso em: 4 de abril 2014.

ANSARAH, M.G.R. (Org.). Turismo: Como aprender, como ensinar. São Paulo: Editora SENAC, 2001. 406 p.

BACELAR, T. As Políticas Públicas no Brasil: heranças, tendências e desafios. Disponível em: $<$ http://fase.org.br/v2/admin/anexos/acervo/10 Tania\%20Bacelar 04doc>.

Acesso em 13 de ago. 2014.

BRASIL. Constituição da República Federativa do Brasil de 1988.

BRASIL. Lei Complementar $n^{\circ} \mathbf{1 4 0}$ de 8 de dezembro de 2011. Fixa normas, nos termos dos incisos III, VI e VII do caput e do parágrafo único do art. 23 da Constituição Federal, para a cooperação entre a União, os Estados, o Distrito Federal e os Municípios nas ações administrativas decorrentes do exercício da competência comum relativas à proteção das paisagens naturais notáveis, à proteção do meio ambiente, ao combate à poluição em qualquer de suas formas e à preservação das florestas, da fauna e da flora; e altera a Lei no 6.938, de 31 de agosto de 1981. 
BRASIL. Grupo de Trabalho Interministerial MICT/MMA. Diretrizes para uma política nacional de Ecoturismo. Brasília: EMBRATUR, 1994.

BRASIL. Lei $n^{\circ}$ 9.985, de 18 de julho de 2000. Regulamenta o art. 225, § 10, incisos I, II, III e VII da Constituição Federal, institui o Sistema Nacional de Unidades de Conservação da Natureza e dá outras providências.

CASTRO, I.E. Turismo e ética. In: CORIOLANO, L.N.M.T. (org.) Turismo com ética. Fortaleza: UECE, 1998, p.15-31.

COLES, T; DUVAL, D. T; HALL, M. Sobre el turismo y la movilidad en tiempos de movimiento y conjetura posdisciplinar. Política y Sociedad. 2005. p. 85-99.

CRUZ, R.C.A. Introdução a geografia do turismo. São Paulo: Roca, 2001.

CRUZ, R.C.A. Política de Turismo e Território. São Paulo: Contexto, 2000.

CUSTÓDIO, D. V. A Importância do Planejamento Urbano-Ambiental para o Crescimento Sustentável do Setor Turístico. In: BARBOSA, L.G.M. ZOUAIN, D.M. (Orgs). Gestão em Turismo e Hotelaria: Experiências Públicas e Privadas. São Paulo: Aleph, 2004. p. 55-71.

DESLAURIERS, J. P. Recherche qualitative: guide pratique. Quebec (CA). McGrawHill, 1991.

DONAIRE, D. Considerações sobre a variável ecológica, as organizações e o turismo. In: LAGE, B. H. G.; MILONE, P. C. Turismo: teoria e prática. São Paulo: Atlas, 2000. cap.6 p. 80-84.

EASTON, D. The political system. N. Y. Knopf, 1953.

FLORIANI, D. Marcos conceituais para 0 desenvolvimento da interdisciplinaridade. In: PHILIPPI JR, A.; TUCCI, C.E.M.; HOGAN, D.J.; NAVEGANTES, R. Interdisciplinaridade em Ciências Ambientais. São Paulo: Signus, p. 95-107, 2000.

FONTELES, J.O. Turismo e Impactos Socioambientais. Aleph. São Paulo. 2004.

FREY, K. A dimensão político-democrática nas teorias de desenvolvimento sustentável e suas implicações para a gestão local. Ambiente \& Sociedade, Campinas, v. 4, n. 9, p.115-148, ago/dez. 2001.

GARROD, B; FYALL, A. Beyond the rhetoric of sustainable tourism? Tourism Management. Reino Unido: Elsevier Science. V.19, n.3, p. 199-212, 1998.

GETZ, D., Tourism planning and research: Traditions, models and futures, ensaio apresentado no The Australian Travel Research Workshop, Bunbury, Western Autralia, 5-6/novembro, 1987.

GOELDNER, C.R; RITCHIE, J.R.B; McINTOSH, R.W. Turismo: princípios, práticas e filosofias. Trad. Roberto Cataldo Costa. 8.ed. Porto Alegre: Bookman, 2002. p. 293-312

HALL, C.M. Planejamento Turístico: Políticas, Processos e Relacionamentos. Contexto, São Paulo. 2001. 
HAWKINS, D.E; LINDEBERG, K. (editores). Ecoturismo: um guia para planejamento e gestão. São Paulo: SENAC, 1999.

HECLO, H. Policy analysis. British Journal of Political Science, v. 2, n. 1, p. 83-108, 1972.

INSTITUTO BRASILEIRO DE GEOGRAFIA E ESTATISTICA. Disponível em: http://www.ibge.gov.br/cidadesat/topwindow.htm?1. Acesso em: 29 ago. 2011.

INSTITUTO BRASILEIRO DE GEOGRAFIA E ESTATISTICA. Pesquisa nacional por amostra de domicílios: síntese de indicadores 1996. Rio de Janeiro: IBGE, 1997.

LEFF, E. Complexidade, Interdisciplinaridade e Saber Ambiental. In: PHILIPPI JR, A.; TUCCI, C.E.M. HOGAN, D.J. NAVEGANTES, R. Interdisciplinaridade em Ciências Ambientais. São Paulo: Signus. 2000.

LUCHIARI, M.T. Urbanização Turística: um novo nexo entre o lugar e o mundo. In: LUCHIARI, M.T.; BRUHNS, H. T.; SERRANO, C. (Orgs). Olhares Contemporâneos sobre o Turismo. Campinas: Papirus, 3.e.d. 2004, cap.5, p.108.

MACHADO, E.M. ; KYOSEN, R.O. Política e Política Social. Serviço Social em Revista, Londrina: v. 3, 2000. Disponível em: http://www.uel.br/revistas/ssrevista/c v3n1 politica.htm. Acesso em 2 abril. 2014.

MAROTI, P.S. Educação e percepção ambiental das comunidades do entorno de uma unidade de conservação. Tese de Doutorado em Ciências - Programa de Pós-Graduação em Ecologia e Recursos Naturais, Universidade Federal de São Carlos. São Carlos, 2002.

MCIYNTYRE, G. Sustainable tourism development: guide for local planners. Madri: WTO, 1993.

MINAYO, M.C. (Org.). Pesquisa social: teoria, método e criatividade.

Petrópolis: Vozes, 2001.

MINAYO, M.C.S.; MINAYO-GOMES,C. Difíceis e possíveis relações entre métodos quantitativos e qualitativos nos estudos de problemas de saúde. In: GOLDENBERG, P.; MARSIGLIA, R.M.G.; GOMES, M.H.A. (Orgs). 0 clássico e o novo: tendências, e abordagens em ciências sociais e saúde. Rio de Janeiro: Fiocruz, 2003. p.17-42.

MORAES, L.C.A. Sistema integrado de gestión como una herramienta para la conservación del ambiente para la práctica del turismo: una propuesta metodologica. TURyDES. vol.7, n¹6, 2014. Disponível em: http://www.eumed.net/rev/turydes/16/sistema-integrado.html.

MOSAICO MANTIQUEIRA. Disponível em: http://mosaicomantiqueira.org.br. Acesso em: 29 ago. 2011.

MOTA, M.; PEREIRA, D.Q.; PEREIRA, V.P. Direito ambiental das cidades: novas perspectivas acerca da sustentabilidade das regiões urbanas. In: Anais do XV Encontro preparatório para o XV Encontro Nacional de Conpedi. Recife, 2006. Florianópolis: Fundação Boiteux. 2006. 
OLIVEIRA, J.A.P. Implementing environmental policies in developing countries through decentralization: the case of protected areas in Bahia, Brasil. World Development (Elsevier Science). 202. p.1713-1736.

OMT. Turismo internacional: uma perspectiva global. 2. ed. São Paulo: Bookman, 2003.

ORGANIZAÇÃO MUNDIAL DE TURISMO (OMT). World Tourism Organization - WTO. Sustainable tourism development: guide for local planners, Madrid: WTO, 1993.

ORGANIZAÇÃO MUNDIAL DE TURISMO. Guia de desenvolvimento do turismo sustentável. Tradução de Sandra Netz. Porto Alegre: Bookman, 168p. 2003.

PETROCCHI, M. Turismo: Planejamento e Gestão. Futura. São Paulo. 1998.

RESENDE. Lei Orgânica do Município de Resende. 1990 (atualizada em 1999).

RESENDE. Lei $\mathbf{n}^{\circ} \mathbf{3 0 0 0}$ de 22 de janeiro de 2013. Institui o Plano Diretor do Município de Resende. Resende. 2013.

RESENDE. Lei n. 1.845 de 20 de maio de 1994. Resende, 1994.

RODRIGUES, A. B. Turismo e Desenvolvimento Local. São Paulo, SP: Hucitec, 3르 ed. 2002.

SALVATTI, S.S. (Org.). Turismo responsável: manual para políticas públicas. Brasília: WWF Brasil, 2004.

SANO,H.; MONTENEGRO FILHO, M.J.F. As Técnicas de Avaliação da Eficiência, Eficácia e Efetividade na Gestão Pública e sua Relevância para o Desenvolvimento Social e das Ações Públicas. Revista Desenvolvimento e Questão. Editora Unijuí, ano 11, n. 22, jan./abr. 2013.

SANTOS FILHO, J. In BAHL, M. (Org.). Turismo: enfoques teóricos e práticos. São Paulo: Roca, 2003.

SEBRAE. Políticas Públicas: conceitos e práticas. Supervisão por Brenner Lopes e Jefferson Ney Amaral; coordenação de Ricardo Wahrendorff Caldas - Belo Horizonte: Sebrae/MG. v.7. 48p. 2008.

SOUZA, N.M. Educação ambiental: dilemas da pratica contemporânea. Rio de Janeiro: THEX, 2000.

SECCHI, Leonardo. Políticas Públicas: Conceitos, Esquemas de Análise, Casos Práticos. São Paulo: Cengage Learning, 2010. 133 p.

SOS MATA ATLANTICA, A Mata Atlântica. Disponível em: http://www.sosma.org.br/nossa-causa/a-mata-atlantical. Acesso em: 05 de abril de 2015.

SERRANO, C.M.T. A vida e os parques: proteção ambiental, turismo e conflitos de legitimidade em unidades de conservação. In: SERRANO, C.M. T.; BRUHNS, H.T. (orgs.). Viagens à natureza: turismo, cultura e ambiente. 4 ed. Campinas: Papirus, 2001. 
SILVA, C.L. Desenvolvimento sustentável: um conceito multidisciplinar. In: SILVA, C.L.; MENDES, J.T.G. (Org.). Reflexões sobre o desenvolvimento sustentável: agentes e interações sob a ótica multidisciplinar. Petrópolis: Vozes, 2005, v. 1, p. 11-40.

SOUZA, C. Estado da Arte da Pesquisa em Políticas Públicas. In: HOCHMAN, G.; ARRETCHE, M.; MARQUES, E. (Orgs.). Políticas Públicas no Brasil. Rio de Janeiro: FIOCRUZ, 2007.

STIEFEL, M; WOLFE, M.A. A voice for the excluded popular participation in develoopmente. Londres: Zed Books, 1994.

SWARBROOKE, J. Turismo Sustentável: conceitos e impacto ambiental. São Paulo: Aleph, 2000. 140 p.

THE INTERNATIONAL ECOTOURISM SOCIETY. Disponível em: http://www.ecotourism.org/site/c.orLQKXPCLmF/b.4835303/k.BEB9/What is Ecotourism The International Ecotourism Society.htm. Acesso em: 2 de dez. 2011.

TRIVIÑOS, A. Introdução à pesquisa em ciências sociais: a pesquisa em educação. São Paulo: Altas, 1987.

WHEELLER, B. Tourism's Troubled Times: responsible tourism is not the answer. Tourism Management, $\mathrm{n}^{\circ} 2$, v. 12. Kent: Butterworth Heineman. 1991. p. 91-118.

ZOUAIN, D.M; CRUZ, F.O. Gestão Social no Sistema Turístico Brasileiro: limites e possibilidades. In: BARBOSA, L.G.M; ZOUAIN, D.M. (Orgs.) Gestão em Turismo e Hotelaria: experiências públicas e privadas. São Paulo: Aleph, 2004.

Luís Carlos Araújo Moraes: GG, Brasil.

E-mail: Icambien@hotmail.com.

Link para o currículo Lattes: http://lattes.cnpq.br/8094630949355388

Data de submissão: 28 de abril de 2015

Data de recebimento de correções: 17 de agosto de 2015

Data do aceite: 17 de agosto de 2015

Avaliado anonimamente 